\title{
Analysis of the efficacy, safety, and regulatory status of novel forms of creatine
}

\author{
Ralf Jäger - Martin Purpura $\cdot$ Andrew Shao $\cdot$ \\ Toshitada Inoue $\cdot$ Richard B. Kreider
}

Received: 10 July 2010/Accepted: 30 November 2010/Published online: 22 March 2011

(C) The Author(s) 2011. This article is published with open access at Springerlink.com

\begin{abstract}
Creatine has become one of the most popular dietary supplements in the sports nutrition market. The form of creatine that has been most extensively studied and commonly used in dietary supplements is creatine monohydrate (CM). Studies have consistently indicated that $\mathrm{CM}$ supplementation increases muscle creatine and phosphocreatine concentrations by approximately $15-40 \%$, enhances anaerobic exercise capacity, and increases training volume leading to greater gains in strength, power, and muscle mass. A number of potential therapeutic benefits have also been suggested in various clinical populations. Studies have indicated that CM is not degraded during normal digestion and that nearly $99 \%$ of orally ingested $\mathrm{CM}$ is either taken up by muscle or excreted in urine. Further, no medically significant side effects have been reported in literature. Nevertheless, supplement manufacturers have continually introduced newer forms of creatine
\end{abstract}

Invited paper presented at the Creatine in Health and Sport 2010 conference. Submitted to Amino Acids, 15 June 2010.

R. Jäger $\cdot$ M. Purpura

Increnovo LLC, 2138 E Lafayette Pl, Milwaukee,

WI 53202, USA

\author{
A. Shao \\ Council for Responsible Nutrition, 1828 L Street NW, \\ Suite 510, Washington, DC 20036, USA \\ T. Inoue \\ Healthy Navi Co., Ltd., 3-18-1-801, Minami-rokugo, \\ Ota-ku, Tokyo 144-0045, Japan \\ R. B. Kreider $(\square)$ \\ Exercise and Sport Nutrition Lab, Department of Health and \\ Kinesiology, Texas A\&M University, 158 Read Building, \\ TAMU 4243, College Station, TX 77843-4243, USA \\ e-mail: rkreider@hlkn.tamu.edu
}

into the marketplace. These newer forms have been purported to have better physical and chemical properties, bioavailability, efficacy, and/or safety profiles than CM. However, there is little to no evidence that any of the newer forms of creatine are more effective and/or safer than CM whether ingested alone and/or in combination with other nutrients. In addition, whereas the safety, efficacy, and regulatory status of $\mathrm{CM}$ is clearly defined in almost all global markets; the safety, efficacy, and regulatory status of other forms of creatine present in today's marketplace as a dietary or food supplement is less clear.

Keywords Creatine $\cdot$ Dietary supplements . Ergogenic aids $\cdot$ Exercise $\cdot$ Performance

\section{Introduction}

Creatine ( $N$-(aminoiminomethyl)- $N$-methyl glycine) is an ingredient commonly found in food, mainly in fish and meat, and is sold as a dietary supplement in markets around the world. Its use as an ergogenic aid and possible treatment for certain neuromuscular disorders is well documented in scientific literature (Buford et al. 2007; Kreider et al. 2010). In recent years, the popularity of creatine has risen dramatically, especially among athletes. In the USA alone, creatine-containing dietary supplements make up a large portion of the estimated $\$ 2.7$ billion in annual sales of sports nutrition supplements (NBJ 2009).

Accompanying this explosive growth in sales has been the introduction of different forms of creatine. Creatine monohydrate (CM), first marketed in the early $1990 \mathrm{~s}$, is the form most commonly found in dietary supplement/food products and most frequently cited in scientific literature. The introduction into the marketplace of alternate forms of 
creatine, beginning in the late 1990s, was presumably an attempt to differentiate the multitude of creatine-containing products available to consumers and improve certain attributes such as solubility and efficacy. However, the legal and regulatory status of these various forms of creatine in the USA and other markets around the world is at best uncertain. To date, with the exception of Japan, CM is the only form of creatine to be officially approved or accepted in key markets such as the USA, European Union (EU), Canada and South Korea. The continued presence of other forms of creatine in the marketplace, especially in the US, may be due to a multitude of factors. These include, but may not be limited to, a lack of awareness or understanding on the part of marketers of applicable laws and regulations, intentional noncompliance with the law, and/or inadequate enforcement of the law. The public health implications of widespread distribution and use of these unauthorized forms of creatine is unknown and warrants careful monitoring.

New forms of creatine are marketed with claims of improved physical, chemical, and physiological properties in comparison to $\mathrm{CM}$. Claims include improved stability when combined with other ingredients or in liquids, improved solubility in water, improved bioavailability, and even an increase in performance. This review will evaluate the available literature on new forms of creatine and compare them to available data on CM in terms of efficacy and safety. In addition, the current international regulatory status of the various forms of creatine that are commercially available will be examined.

\section{Methods}

This analysis represents a systematic review of the literature on the various forms of creatine available in the global marketplace as dietary supplements, food supplements, or natural health products. For technical and performance comparisons, literature searches were performed by searching the Medline database of the US National Library of Medicine of the National Institutes of Health. The search strategy involved entering the various creatine search terms (Table 1), along with the technical or performance aspect of interest (e.g., solubility, stability, bioavailability, performance). In addition, a patent research was performed by searching the database of the World Intellectual Property Organization (WIPO), the European Patent Office, the Japan Patent Office, and the United States Patent and Trademark Office. Articles were reviewed, analyzed, and interpreted, with results of the relevant studies presented below.

For the assessment of the current regulatory status of the various forms of creatine, the Web sites of regulatory
Table 1 Creatine content of different forms of creatine

\begin{tabular}{lll}
\hline Form of creatine & $\begin{array}{l}\text { Creatine } \\
\text { content }(\%)\end{array}$ & $\begin{array}{l}\text { Difference } \\
\text { in CM }(\%)\end{array}$ \\
\hline Creatine anhydrous & 100.0 & +13.8 \\
CM & 87.9 & 0 \\
Creatine ethyl ester & 82.4 & -6.3 \\
Creatine malate (3:1) & 74.7 & -15.0 \\
Creatine methyl ester HCl & 72.2 & -17.9 \\
Creatine citrate (3:1) & 66 & -24.9 \\
Creatine malate (2:1) & 66 & -24.9 \\
Creatine pyruvate & 60 & -31.7 \\
Creatine $\alpha$-amino butyrate & 56.2 & -36.0 \\
Creatine $\alpha$-ketoglutarate & 53.8 & -38.8 \\
Sodium creatine phosphate & 51.4 & -41.5 \\
Creatine taurinate & 51.4 & -41.6 \\
Creatine pyroglutamate & 50.6 & -42.4 \\
Creatine ketoisocaproate & 50.4 & -42.7 \\
Creatine orotate (3:1) & 45.8 & -47.9 \\
Carnitine creatinate & 44.9 & -49.0 \\
Creatine decanoate & 43.4 & -50.7 \\
Creatine gluconate & 40.2 & -54.3 \\
\hline
\end{tabular}

bodies for key markets around the world were accessed (USA: US Food and Drug Administration; Canada: Health Canada; EU: European Commission; Japan: Ministry of Health, Labor and Welfare; Korea: Korea Food and Drug Administration). Information derived from these sites was used to determine the legal and regulatory framework governing creatine products in these markets and the current regulatory status of the various forms of creatine as dietary supplements, food supplements, and natural health products.

\section{Physio-chemical properties}

Creatine crystallizes from water as monoclinic prisms holding one molecule of water of crystallization per molecule of creatine. Continued drying of CM results in a loss of the water of crystallization at around $100^{\circ} \mathrm{C}$, yielding anhydrous creatine. Creatine is a weak base with a $p k b$ value of 11.02 at $25^{\circ} \mathrm{C}$. As a result, creatine can only form salts with strong acids, having a $p k a$ value of less than 3.98. Creatine forms salts by the protonation of its guanidine moiety (see Fig. 1). In addition to salt formation, creatine is able to act as a complexing agent.

Creatine salts such as citrate, maleate, fumarate, tartrate (Negrisoli and Del Corona 1997), pyruvate (Pischel and Weiss 1996), ascorbate (Pischel et al. 1999), and orotate (Abraham and Jiang 2005) were first introduced to the marketplace as early as the late 1990s. Creatine and acids 


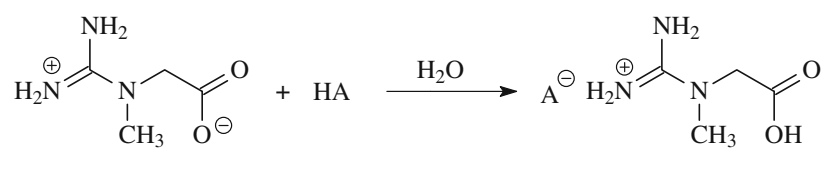

Creatine

Strong Acid

Creatine-Salt

Fig. 1 Creatine salts

with multiple acid moieties such as citric acid can form salts as well as complexation products. The first acid moiety of citric acid is strong enough $(p k a=3.09)$ to form a salt with creatine; however, the other two moieties ( $p k a 2=4.75, p k a 3=5.41)$ should only be able to form complexes with creatine. A salt, a salt-complex combination, or a simple physical mixture can be differentiated by measurement of the enthalpy changes of neutralization, which ranges usually in the area of -55 to $-66 \mathrm{~kJ} / \mathrm{mole}$ for the salt formation to less than $-5 \mathrm{~kJ} / \mathrm{mole}$ for the change in complexation enthalpy to no changes in enthalpy for a physical mixture (1995). A "tricreatine citrate" is actually a complex of creatine citrate with two additional creatine moieties, resulting in a molecule with a ratio of creatine to citrate of $3: 1$.

In addition to creatine and its salts, derivatives of creatine such as creatine ester or even creatine alcohols are currently marketed as dietary supplements in the USA (see Fig. 2). Both ingredients do not contain creatine as such, since they have been chemically altered. While it is assumed that the human body will transfer those molecules into creatine upon intake, there are no published data available to base firm conclusions.

The amount of creatine in different forms of creatine varies. Creatine monohydrate contains $87.9 \%$ of creatine, whereas the creatine content in other forms of creatine is lower with the exception of creatine anhydrous (see Table 1). Commercial creatine salts are formed in solution or by mechanical processes such as milling or grinding under the presence of residual water. Complexes are formed by the subsequent replacement of the solvating molecules by the new ligands.

\section{Solubility}

One major limitation of creatine as an ampholytic amino acid is its rather low solubility in water. The solubility of creatine in water increases with temperature and the

Fig. 2 Chemical structure of creatine and creatine derivatives correlation between solubility and temperature is almost linear. One liter of water dissolves $6 \mathrm{~g}$ of creatine at $4^{\circ} \mathrm{C}$, $14 \mathrm{~g}$ at $20^{\circ} \mathrm{C}, 34 \mathrm{~g}$ at $50^{\circ} \mathrm{C}$, and $45 \mathrm{~g}$ at $60^{\circ} \mathrm{C}$. The solubility of creatine can also be increased by lowering the $\mathrm{pH}$ of the solution. This principle is the basis for the improved solubility of creatine salts, since creatine salts lower the $\mathrm{pH}$ of water due to the nature of acid moiety. Creatine monohydrate dissolves at $14 \mathrm{~g} / \mathrm{L}$ at $20^{\circ} \mathrm{C}$ resulting in a neutral $\mathrm{pH}$ of 7. A saturated solution of tricreatine citrate in water has a $\mathrm{pH}$ of 3.2 ; whereas a saturated solution of creatine pyruvate even has a $\mathrm{pH}$ of 2.6 (pyruvic acid is a stronger acid than citric acid). The decrease in $\mathrm{pH}$ results in an increase in solubility: $29 \mathrm{~g} / \mathrm{L}$ creatine citrate at $20^{\circ} \mathrm{C}$, and $54 \mathrm{~g} / \mathrm{L}$ creatine pyruvate at $20^{\circ} \mathrm{C}$. Normalized by the relative amount of creatine per molecule (monohydrate $87.9 \%$, citrate $66 \%$, pyruvate $60 \%$ ), creatine citrate (19.14 g/L) shows a 1.55-fold and creatine pyruvate (32.4 g/L) a 2.63-fold better solubility when compared with the monohydrate $(12.3 \mathrm{~g} / \mathrm{L})$. Whereas the creatine derivative creatinol- $O$-phosphate $\left(5 \mathrm{~g} / \mathrm{L}\right.$ at $\left.20^{\circ} \mathrm{C}\right)$ has inferior solubility, dicreatinol sulfate $\left(1,370 \mathrm{~g} / \mathrm{L}\right.$ at $\left.20^{\circ} \mathrm{C}\right)$ shows superior solubility when compared with $\mathrm{CM}$, creatine salts, or creatine esters (Godfraind et al. 1983; Gastner et al. 2005).

Stability

\section{Stability in solid form}

Creatine monohydrate powder is very stable showing no signs of degradation over years, even at elevated temperatures. To detect a potential degradation of creatine, one must measure the content of its degradation product, creatinine (see Fig. 3), which can be quantified by HPLC at levels as low as 67 parts per million (ppm). At room temperature and even at an increased temperature of $40^{\circ} \mathrm{C}$ $\left(104^{\circ} \mathrm{F}\right), \mathrm{CM}$ shows no signs of degradation (i.e., creatinine levels stay under the quantification limit of $67 \mathrm{ppm}$ ) after more than 3 years. As Fig. 3 shows, even when stored at $60^{\circ} \mathrm{C}\left(140^{\circ} \mathrm{F}\right)$, creatinine $(106 \mathrm{ppm})$ was only detected after a period of 44 months (Jäger 2003).

\section{Stability in solutions}

As shown in Fig. 4, in contrast to its stability in a solid state, creatine is not stable in aqueous solution due to an<smiles>CN(CC(=O)[O-])C(N)=[NH2+]</smiles>

Creatine<smiles>CCOC(=O)CN(C)C(=N)N</smiles>

Creatine Ethylester<smiles>CN(CCOP(=O)(O)O)C(=N)N</smiles>

Creatinol-O-Phosphate 

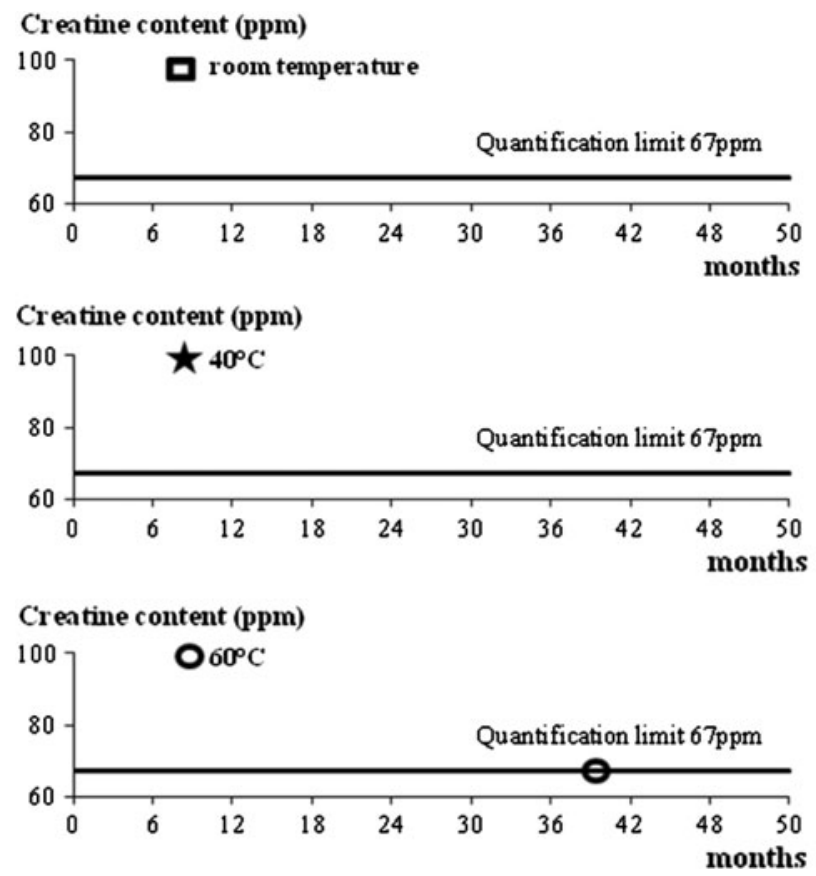

Fig. 3 Stability of creatine monohydrate powder. Adapted from Jäger (2003)

intramolecular cyclization (Howard and Harris 1999). The rate of creatine degradation in solution is not dependent on its concentration, but on $\mathrm{pH}$. Generally, the lower the $\mathrm{pH}$ and higher the temperature, the faster is the degradation. This solid-state and degradation properties have been thoroughly investigated as early as the 1920s (Edgar and Shiver 1925; Cannon et al. 1990) and more recently by Dash et al. (2002), as well as Harris et al. (Howard and Harris 1999). These researchers found that whereas creatine was relatively stable in solution at neutral $\mathrm{pH}(7.5$ or 6.5), a lowering of $\mathrm{pH}$ resulted in an increased rate of degradation and after only 3 days of storage at $25^{\circ} \mathrm{C}$ creatine degraded significantly: $4 \%$ at $\mathrm{pH} 5.5 ; 12 \%$ at $\mathrm{pH} 4.5$; and $21 \%$ at pH 3.5 (see Fig. 5). Similarly, Ganguly et al. (2003) reported that creatine monohydrate stored at room temperature degraded into creatinine within several days but that refrigerating creatine monohydrate in solution slowed degradation. The rapid degradation of creatine in solution precludes the manufacture of shelf-stable standard acidic beverages containing efficacious amounts of the

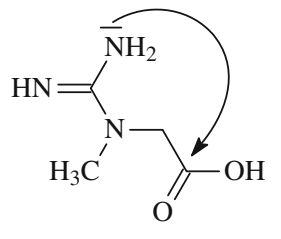

Creatine

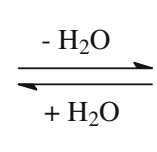

$\mathrm{H}_{3} \mathrm{C}$

Creatinine
Fig. 4 Degradation of creatine to creatinine

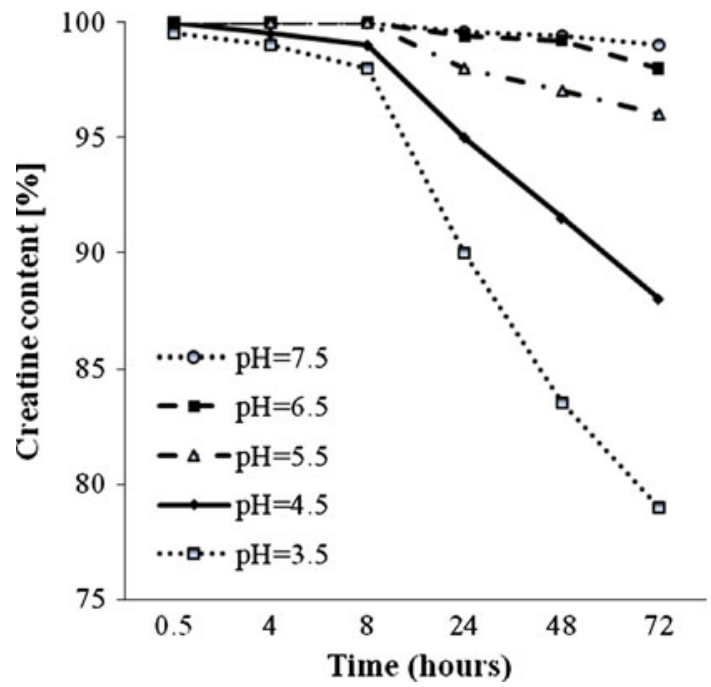

Fig. 5 Effect of pH on creatine stability in solution. Adapted from Howard and Harris (1999)

ingredient. If creatine is not consumed immediately after it has been dissolved in water, it should be stored at a low temperature to retard the degradation.

The degradation of creatine can be reduced or even halted by either lowering the $\mathrm{pH}$ under 2.5 or increasing the $\mathrm{pH}$. A very high $\mathrm{pH}$ results in the deprotonation of the acid group, thereby slowing down the degradation process by making it more difficult for the intramolecular cyclization. A very low $\mathrm{pH}$ results in the protonation of the amide function of the creatine molecule, thereby preventing the intramolecular cyclization (see Fig. 6). This effect also occurs under the acidic conditions in the stomach, hence preventing the breakdown of creatine. The conversion of creatine to creatinine in the gastrointestinal tract is minimal regardless of transit time (Persky et al. 2003; Harris et al. 1992b; Deldicque et al. 2008).

\section{Stability of other forms of creatine}

Some creatine salts appear to be less stable when compared with CM. Tricreatine citrate results in creatinine levels of $770 \mathrm{ppm}$ at $40^{\circ} \mathrm{C}\left(104^{\circ} \mathrm{F}\right)$ after 28 days of storage. However, the addition of carbohydrates has been shown to increase stability of some creatine salts (Purpura et al. 2005). Creatine salts are not expected to have a greater stability in solution; however, the $\mathrm{pH}$ lowering effect of the salt might reduce stability compared to $\mathrm{CM}$ in the same environment.

Tallon et al. (Child and Tallon 2007) compared the stability of creatine ethyl ester (CEE) head to head with $\mathrm{CM}$ and found that CEE was actually less stable than CM. It was concluded that the addition of the ethyl group to creatine actually reduced acid stability and accelerated its breakdown to creatinine. The degradation of creatine and 
Fig. 6 Very low pH prevents creatine degradation

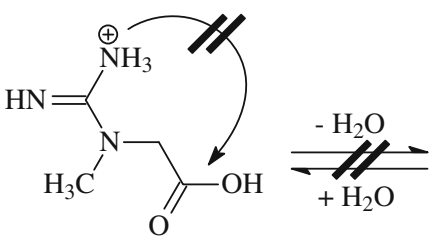

Creatine at very low $\mathrm{pH}$

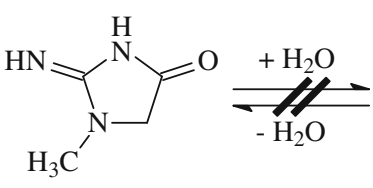

Creatinine<smiles>C=C1CCNC(=N)N(C)CC(=O)O1</smiles>

Creatine at very high $\mathrm{pH}$
Fig. 7 Degradation of creatine and creatine ester

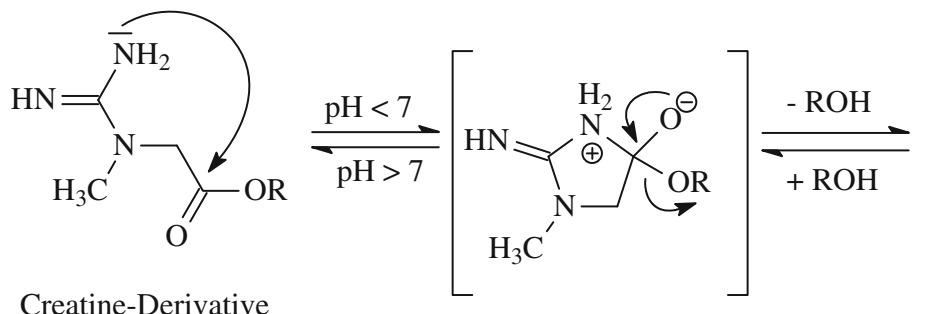

Creatine-Derivative<smiles>CN1CC(=O)NC1=N</smiles>

Creatinine

$\mathrm{R}=\mathrm{OH}($ Creatine $)$

$\mathrm{R}=\mathrm{OC}_{2} \mathrm{H}_{5}$ (Creatine Ethyl Ester)

$\mathrm{R}=\mathrm{OCH}_{3}$ (Creatine Methyl Ester)

creatine ester involves intramolecular hydrolysis of a carboxyl acid (in case of creatine) or carboxylic ester (in case of creatine methyl- or ethyl ester) under acidic conditions and the rate of degradation depends on the leaving group (see Fig. 7). It is speculated that the methyl ester or ethyl ester groups are better leaving groups than hydroxyl or water and, therefore, suggesting that the degradation into creatinine should be rather accelerated.

These findings are also in accordance with the recent investigations on the stability of $\mathrm{CEE}$ at $37^{\circ} \mathrm{C}$ in both water and phosphate-buffered saline and the in vitro response of CEE to incubation in human plasma by H-NMR analysis (Giese and Lecher 2009b). The conversion of CEE to creatine by the esterases in human plasma was not detected, and the only species detected after the incubation period was creatinine. It is concluded that CEE is mostly converted into creatinine under physiological conditions encountered during transit through the various tissues, suggesting no ergogenic effect is to be expected from supplementation of CEE. The high stability of CM is well documented, whereas the stability of newer forms of creatine (salts, ester, etc.) either has not been investigated or appears to be inferior. New forms of creatine contain less of the active principal creatine in comparison to $\mathrm{CM}$; however, creatine salts can offer an advantage over CM with regard to solubility.

\section{Bioavailability}

The uptake of creatine is simplified in a two-step approach: first, uptake into the blood stream; second, uptake into the target tissue. The term 'bioavailability' refers to both the intestinal absorption and the use of a substance by the body's cells and tissues. First indications of a potential change of creatine bioavailability can be gathered from the amount of creatine taken up into the blood plasma after oral administration. However, a change in the total amount of creatine in the blood plasma cannot be directly extrapolated to a potential increase in desired performance. An increased amount of creatine in the plasma could be the result of decreased uptake into the target tissue resulting in an actual decrease in overall bioavailability. On the other hand, an initial rise in plasma creatine levels, followed by a reduction in plasma levels, is an indication of increased uptake into the target tissue. This has been demonstrated in vivo by combining creatine with insulin-stimulating ingredients such as high amounts of glucose or protein (Bessman and Mohan 1992; Haughland and Chang 1975; Rooney et al. 2002). Conclusive proof of an increase in relevant bioavailability can only be gained by assessing the amount of creatine reaching the target tissue, the muscle, measured by muscle biopsy and/or whole body creatine retention assessed by measuring the difference between creatine intake and urinary excretion.

Dietary creatine is presumed to have high bioavailability since intestinal absorption of CM is already close to $100 \%$ (Deldicque et al. 2008). However, the response to creatine supplementation is heterogeneous, due in part to some nonresponders, which might be overcome by alternative forms of creatine (Greenhaff 1997b; Greenhaff et al. 1993). Several studies have examined whether different forms of creatine are more effective in terms of promoting muscle uptake of creatine than CM. For example, a recent study 
examined the effect of the administration of three different forms of creatine on plasma creatine concentrations and pharmacokinetics. In a balanced cross-over designed study, six healthy subjects were assigned to ingest a single dose of isomolar amounts of creatine $(4.4 \mathrm{~g})$ in the form of $\mathrm{CM}$, tricreatine citrate (TCC), or creatine pyruvate (CPY), followed by measurement of the plasma creatine levels (Jäger et al. 2007). Mean peak concentrations and area under the curve (AUC) were significantly higher with CPY (17 and $14 \%$, respectively) in comparison to CM. The findings suggest that different forms of creatine may result in slightly different kinetics of plasma creatine absorption, although differences in velocity constants of absorption could not be detected due to the small number of blood samples taken during the absorption phase. The small differences in kinetics are unlikely to have any clinically relevant effects on muscle creatine elevation during periods of creatine loading. A follow-up study including muscle biopsies would be required to conclude if the bioavailability of this specific creatine salt was indeed higher (Fig. 8).

Greenwood et al. (2003) investigated how different forms of creatine affect whole body creatine retention. Sixteen males were assigned to ingest in a single blind manner either $5 \mathrm{~g}$ of dextrose, $5 \mathrm{~g}$ of CM, $5 \mathrm{~g}$ of CM plus $18 \mathrm{~g}$ dextrose, or an effervescent creatine supplement consisting of $5 \mathrm{~g}$ of TCC ( $66 \%$ creatine) plus $18 \mathrm{~g}$ dextrose four times/day for 3 days. Creatine retention was estimated by subtracting total urinary creatine excretion from total supplemental creatine intake over the 3-day period. Results revealed that average daily creatine retention over the

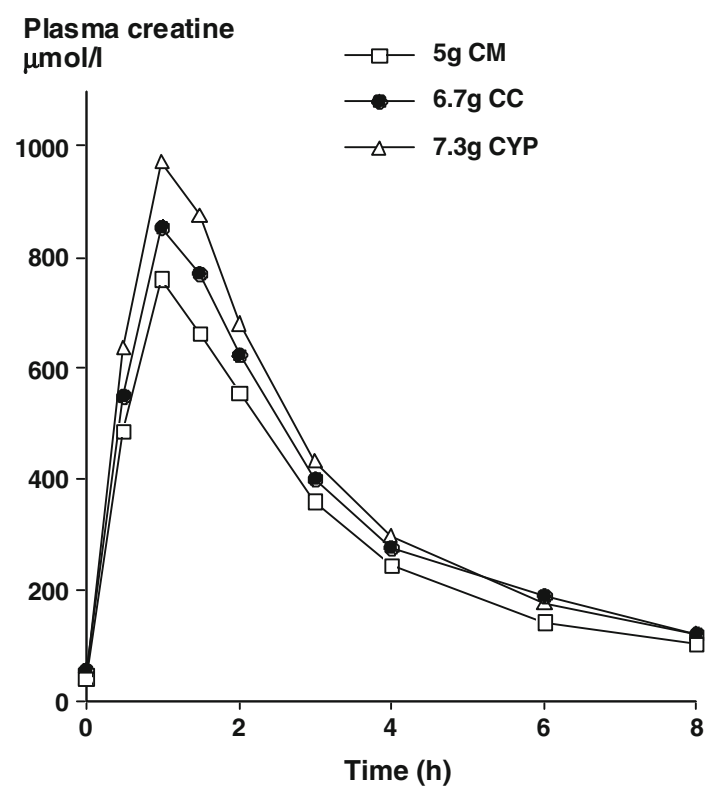

Fig. 8 Comparison of blood plasma levels of different forms of creatine. Adapted from Jäger et al. (2007)
Whole Body Creatine Retention

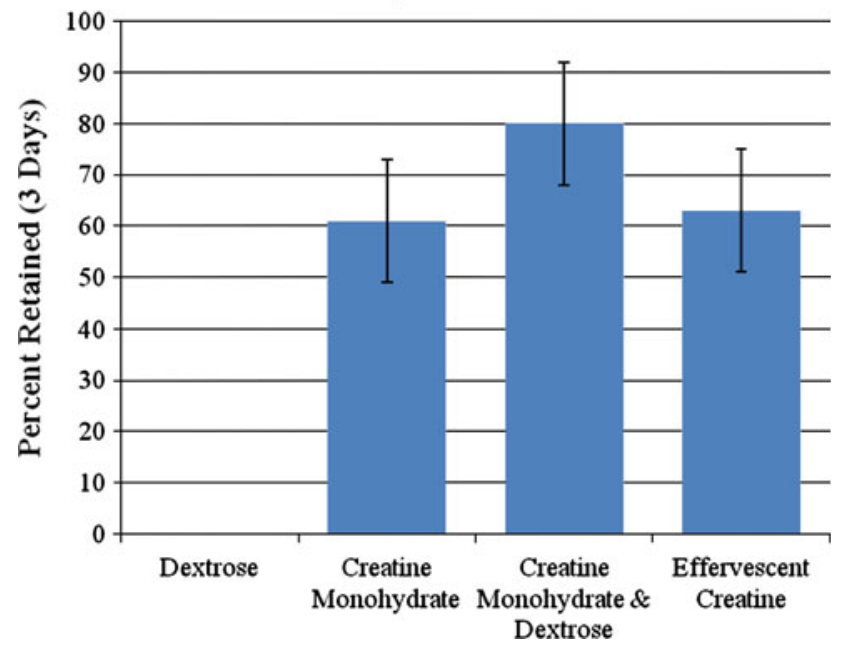

Fig. 9 Percentage of creatine retained during a 3-day loading period (20 g/day). Adapted from Greenwood et al. (2003)

3-day period was $12.2 \pm 1.3,16.1 \pm 2.2$, and $12.6 \pm 2.5 \mathrm{~g} /$ day for the CM, CM with dextrose, and effervescent TCC groups, respectively. This amounted to whole body creatine retention of $61 \pm 15 \%$ for the CM group, $80 \pm 11 \%$ for the $\mathrm{CM}$ plus dextrose group, and $63 \pm 13 \%$ for the effervescent TCC group. While creatine retention was significantly greater in the $\mathrm{CM}$ and dextrose group, no significant differences were seen between the $\mathrm{CM}$ and effervescent TCC groups. These findings suggest that while consuming a relatively small amount of dextrose with $\mathrm{CM}$ can increase whole body creatine retention, supplementation of TCC in an effervescent form does not augment whole body creatine retention more than CM alone (Fig. 9).

Over the years, there has been significant commercial interest in determining whether creatine could be delivered in a liquid form. The thought has been since CM is relatively insoluble that development of a liquid or suspended form of creatine may be more convenient to consume, be more readily absorbed into the blood stream, and promote a greater efficiency in transport of creatine to the muscle. Some companies have even claimed that minimal amounts of liquid creatine would need to be ingested because of enhanced efficiency in transport through the blood and into the muscle. A limitation with these theories is that $\mathrm{CM}$ is not stable for any substantial length of time in liquid. Consequently, while researchers have been working on ways to suspend creatine within gels and fluids, it has been generally considered to be impractical to develop into a product due to limitations in shelf-life. In addition, while people may prefer the taste of liquid or gel versions of creatine, there is no evidence that these delivery forms provide a superior performance benefit.

Kreider et al. (2003b) carefully compared the effects of ingesting $20 \mathrm{~g} /$ day of $\mathrm{CM}$ to recommended doses 
( $2.5 \mathrm{~g} /$ day of $\mathrm{CM}$ ), as well as doses that would purportedly provide an equivalent amount of $\mathrm{CM}$ per day in liquid form ( $20 \mathrm{~g} /$ day) on muscle creatine, phosphocreatine, and total creatine levels. Subjects donated muscle biopsies prior to and following 5 days of supplementing their diet in a randomized and double-blind manner with either $5 \mathrm{~mL}$ of creatine liquid (purportedly providing $2.5 \mathrm{~g}$ of $\mathrm{CM}$ ), $5 \mathrm{~mL}$ of a flavored placebo, $8 \times 5 \mathrm{~mL}$ doses of creatine liquid (purportedly providing $20 \mathrm{~g} / \mathrm{day}$ of $\mathrm{CM}$ ), or $8 \times 5 \mathrm{~mL}$ doses of a flavored placebo. Another group ingested $4 \times 5 \mathrm{~g}$ of $\mathrm{CM}$ for 5 days as a non-blinded benchmark control. This analysis allowed for a comparison of ingesting recommended doses of liquid creatine to a placebo, as well as seven times the amount recommended by the manufacturer that would purportedly provide an equal amount of CM. The researchers found that CM supplementation significantly increased muscle free creatine content by $31 \pm 28 \%$. However, none of the other groups experienced any effect on muscle free creatine, phosphocreatine, or total creatine content. Moreover, changes in muscle creatine and phosphocreatine levels in response to $\mathrm{CM}$ supplementation were significantly greater than the liquid creatine and placebo groups. These findings indicate that liquid creatine supplementation has no effect on muscle phosphagen levels and therefore may have no ergogenic value. While other groups have been attempting to develop stable forms of liquid and/or gel forms of creatine with some success, there are no data available to date demonstrating that these types of creatine are absorbed more efficiently and/or have greater benefit compared to CM (Fig. 10).

An alternative dissolved form of creatine is colloidal CM. CM is dissolved in its own crystal water and dispersed into a stable protective matrix containing carbohydrates (Kessel et al. 2004). The product is claimed to be the only solubilized form of powdered creatine in the market,

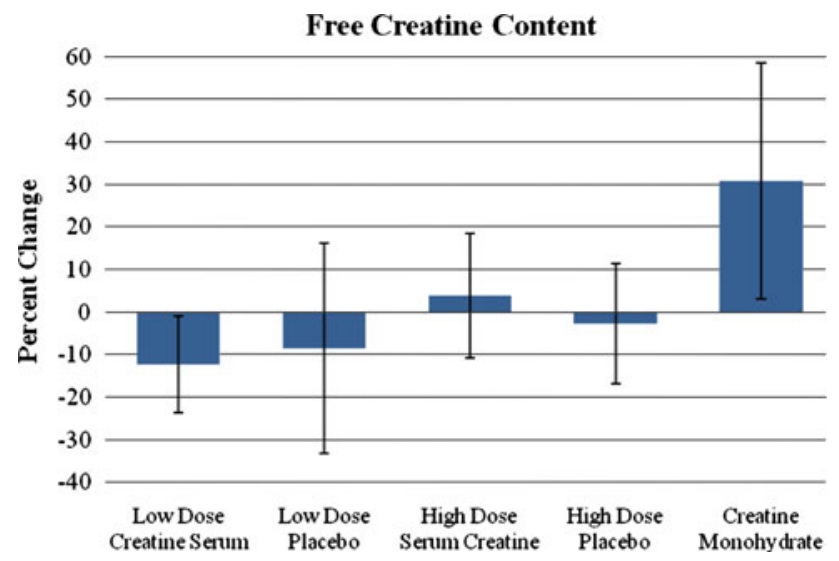

Fig. 10 Change in muscle-free creatine content in response to 5 days of low or high-dose creatine serum and placebo ingestion compared to CM. Adapted from Kreider et al. (2003b) making it more bioavailable and stable. However, no evidence has been published to date to substantiate any performance or ergogenic benefit from this form of creatine.

Creatine ethyl ester has been purported to be a superior form of creatine in comparison to CM. However, prior studies have shown that it degrades rather quickly to creatinine when exposed to low $\mathrm{pH}$ levels as would be found in the stomach (Giese and Lecher 2009a; Katseres et al. 2009). Theoretically, this would reduce the bioavailability of creatine. To test this hypothesis, Spillane et al. (2009) compared the effects of supplementing the diet with a placebo, CM, or CEE during 42 days of training. Serum creatinine and muscle total creatine content was assessed prior to and following 6,27 , and 48 days of supplementation and training. The researchers found that serum creatinine levels were significantly increased in the CEE group after 6, 27, and 48 days of supplementation indicating less efficient bioavailability. In addition, while CEE supplementation promoted a modest increase in muscle total creatine content, it was increased to a greater extent in the $\mathrm{CM}$ group. These findings directly contradict claims that CEE is more effective in increasing muscle creatine stores. Further, the significantly higher creatinine levels observed should raise some potential safety concerns about potential safety (Fig. 11).

Several studies have also evaluated whether co-ingestion of creatine with other nutrients may influence creatine retention. Initial work by Green and colleagues (Green et al. 1996a, b) demonstrated that co-ingesting creatine $(5 \mathrm{~g})$ with large amounts of glucose (e.g., $95 \mathrm{~g})$ enhanced creatine and carbohydrate storage in muscle. Subsequent studies by Steenge et al. (2000) found ingesting creatine $(5 \mathrm{~g})$ with $47-97 \mathrm{~g}$ of carbohydrate and $50 \mathrm{~g}$ of protein also enhanced creatine retention. The researchers suggested that

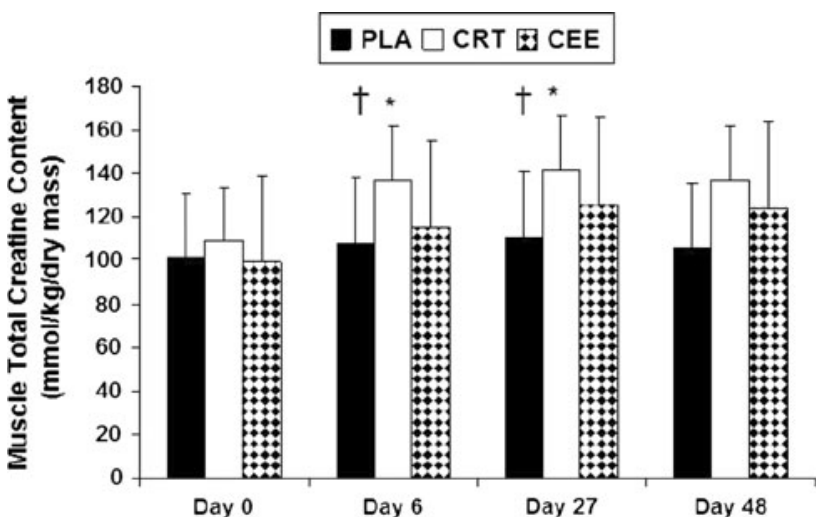

Fig. 11 Changes in total muscle creatine content in response to placebo (PLA), creatine monohydrate $(C R T)$, and creatine ethyl ester (CEE) supplementation (Spillane et al. 2009). 'Significantly different from PLA group. *Significant difference from baseline. Reprinted with permission 
creatine transport was mediated in part by glucose and insulin. As a result, additional research has been undertaken to assess the effect of co-ingesting creatine with nutrients that may enhance insulin sensitivity on creatine retention.

Several studies have examined whether co-ingesting creatine with D-pinitol influences whole body creatine retention. In the first study (Greenwood et al. 2001), 12 male subjects with no history of creatine supplementation donated 24-h urine samples for 4 days. After an initial control day designed to determine normal daily creatine excretion rates, subjects were then matched according to body mass and randomly assigned to ingest in a singleblind manner either a placebo $(4 \times 5 \mathrm{~g}$ doses of dextrose $)$, $\mathrm{CM}(4 \times 5 \mathrm{~g}), \mathrm{CM}$ with low-dose D-pinitol $(4 \times 5 \mathrm{~g} \mathrm{CM}$ with $2 \times 0.5 \mathrm{~g}$ of D-pinitol), or CM with high-dose D-pinitol $(4 \times 5 \mathrm{~g} \mathrm{CM}$ with $4 \times 0.5 \mathrm{~g}$ D-pinitol) for 3 days. Whole body creatine retention was estimated by subtracting total urinary creatine excretion from total supplemental creatine intake over the 3-day period. Results revealed that whole body creatine retention over the 3-day loading period was significantly greater in the low-dose D-Pinitol group in comparison to the group ingesting $\mathrm{CM}$ alone. However, no differences were seen between $\mathrm{CM}$ alone and $\mathrm{CM}$ with the higher dose of D-Pinitol (Fig. 12).

In a follow-up study, Kerksick et al. (2009) examined whether co-ingestion of D-pinitol with CM would affect training adaptations, body composition, and/or whole-body creatine retention in resistance-trained males. In the study, 24 resistance trained males were randomly assigned in a double-blind manner to $\mathrm{CM}+$ D-pinitol or $\mathrm{CM}$ alone prior to beginning a supervised 4-week resistance training program. Subjects ingested a typical loading phase (i.e., $20 \mathrm{~g} /$ day for 5 days) before ingesting $5 \mathrm{~g} /$ day for the remaining

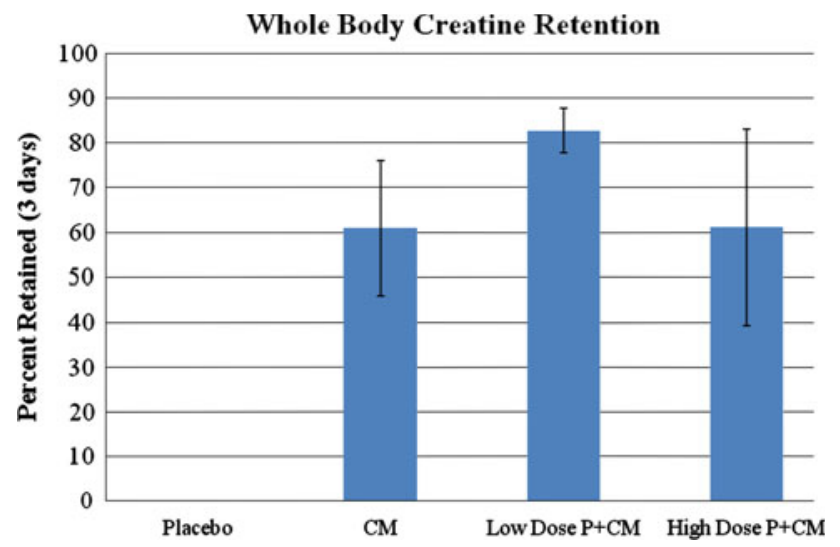

Fig. 12 Change in whole body creatine retention in response to 5 days of placebo, creatine monohydrate $(C M)$, low-dose D-pinitol $(P)$ and $\mathrm{CM}$, and high-dose $\mathrm{P}$ and $\mathrm{CM}$ supplementation. Adapted from Kerksick et al. (2007)
23 days. Results revealed that creatine retention increased in both groups as a result of supplementation. However, no significant differences were observed between groups in training adaptations. Consequently, additional research is needed to determine whether D-pinitol supplementation enhances creatine uptake and/or affects the ergogenicity of creatine supplementation before firm conclusions can be drawn.

Russian tarragon (Artemisia dracunculus) is an ethanolic extract that is often used as a cooking herb. Studies have shown that Russian tarragon (RT) appears to have antihyperglycemic activity when combined with CM ingestion (Jäger et al. 2008a; Wang et al. 2008). Theoretically, ingesting RT extract prior to creatine loading may enhance insulin sensitivity and thereby promote greater creatine absorption/retention. To support this hypothesis, Jäger et al. (2008a) reported that RT influences plasma creatine levels during the ingestion of $\mathrm{CM}$ in a similar manner to glucose and protein. However, further research is needed to evaluate the effects of RT on creatine uptake and retention in muscle before conclusions can be drawn (Fig. 13).

In analysis of this literature, it is clear that CM supplementation promotes significant increases in muscle creatine levels in most individuals. There is some evidence that co-ingestion of $\mathrm{CM}$ with various nutrients (e.g., carbohydrate, protein, D-pinitol) may enhance creatine uptake to a greater degree. However, there is no evidence that effervescent creatine, liquid creatine, and/or CEE promotes greater uptake of creatine to the muscle. Rather, there is some evidence that some of these forms of creatine may be less effective and/or be of greater clinical concern in terms of safety.

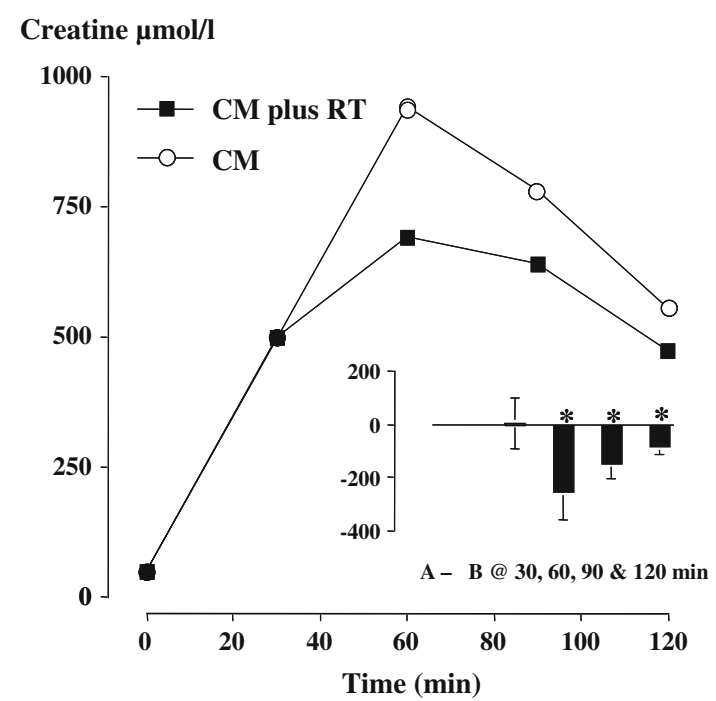

Fig. 13 Influence of Russian tarragon on creatine absorption. Adapted from Jäger et al. (2008a) 


\section{Ergogenic properties}

\section{Creatine monohydrate}

Numerous studies have found that CM supplementation increases muscle phosphagen levels generally by $10-40 \%$ (Greenhaff 1997a; Harris et al. 1992a; Hultman et al. 1996). Acute and chronic supplementation of $\mathrm{CM}$ has been reported to improve performance primarily during high intensity, intermittent activities (Greenhaff 1997a; Kraemer and Volek 1999; Kreider 2003). The impact on performance has been associated with the magnitude of change in baseline phosphagen levels (Burke et al. 2003a; Greenhaff 1997a). Numerous studies have shown that CM supplementation during training promotes greater gains in performance and/or fat-free mass (Cribb and Hayes 2006; Kreider et al. 1998; Volek et al. 1997, 1999; Willoughby and Rosene 2001; Willoughby and Rosene 2003). The only clinically significant side effect reported in literature has been weight gain, which is an attribute desired by many athletes who desire to increase muscle mass as well as clinical populations concerned about muscle wasting (Bender et al. 2008; Dalbo et al. 2008; Kreider et al. 2003a; Schilling et al. 2001). Consequently, CM has proven to be one of the most effective, safe, and well-studied ergogenic aids.

\section{Creatine salts}

Creatine has been combined with different organic acids to form creatine salts with the intention of using acids that will create a synergistic effect or simply improve the properties of creatine. A limitation of this approach is that effective daily doses of creatine and the acid will have to match to achieve meaningful physiological effects. In addition, creatine salts will have to outperform the physical mixture of $\mathrm{CM}$ and the corresponding acid, showing synergistic effects.

Inorganic salts of pyruvic acid have been shown to improve endurance when ingested in high amounts in rats (Ivy 1998), and consequently creatine has been combined with pyruvic acid to form creatine pyruvate (CPY), with the suggested benefit of a synergistic effect between the two. The potential endurance enhancing effects of CPY has been investigated in several studies, using doses of pyruvate significantly lower than previously found to be effective. Two studies investigating the endurance exercise capacity of short-term CPY supplementation showed mixed results. In this regard, 7 days of $7 \mathrm{~g}$ per day CPY supplementation did not beneficially impact endurance capacity or intermittent sprint performance in well-trained cyclists (Van Schuylenbergh et al. 2003), whereas 5 days of $7.5 \mathrm{~g}$ per day CPY intake increased paddling speed and resulted in decreased lactate concentrations in Olympic canoeists, suggesting an increase in aerobic metabolism (Nuuttilla 2000). A recent double-blind, placebo-controlled, randomized study evaluated the effect of oral CPY supplementation on exercise performance in healthy young athletes in comparison to placebo and TCC (Jäger et al. 2008b). It was concluded that 4 weeks of supplementation with creatine salts significantly improved performance during intermittent handgrip exercise of maximal intensity and that CPY might benefit endurance, due to enhanced aerobic metabolism. This study is a first indication that the creatine salt CPY may have potential advantage over CM. However, more research is needed to investigate this effect.

Creatine citrate (CC) has been used in several performance studies; however, none of those studies compared the product to CM. High-dose, short-term CC supplementation ( $4 \times 5 \mathrm{~g} \mathrm{CC}$ per day for 5 days) has been found to increase anaerobic working capacity (AWC) in healthy physically active women (Eckerson et al. 2004) and is able to delay the onset of neuromuscular fatigue during cycle ergometry (Smith et al. 2007). In a recent study, CC supplementation was able to raise the ventilatory threshold during intensity interval training (Graef et al. 2009). Although these studies are interesting, more research is needed particularly comparing $\mathrm{CC}$ to $\mathrm{CM}$ before it can be concluded that $\mathrm{CC}$ has any additional benefits.

Creatine ester

To date, Spillane et al. (2009) are the only group that has studied the impact of CEE supplementation on training adaptations in resistance trained individuals. The researchers randomly assigned in a double-blind manner 30 male resistance-trained athletes to ingest $0.30 \mathrm{~g} / \mathrm{kg}$ per day fat-free mass (about $20 \mathrm{~g} /$ day) of either a placebo, CM, or CEE for 42 days. As stated previously, CEE supplementation did not promote greater total muscle creatine levels in comparison to placebo. In terms of training adaptations, CEE supplementation did not promote greater gains in body mass, fat-free mass, strength, or sprint performance. These findings indicate that CEE has no apparent ergogenic value over CM despite widespread claims that it is a more superior form of creatine. Additionally, the significantly higher creatinine levels observed indicate it is degraded to a greater degree and may pose greater safety concerns.

\section{Creatinol}

Creatinol in the form of creatinol-O-phosphate (COP) has been described and used in subjects with deficient myocardial circulation (Guglielmi and Mammarella 1979). Based on the findings that intravenous administration of $\mathrm{COP}$ in healthy human subjects led to increased values of 
creatinine in urine, it is speculated that creatinol acts as a precursor of creatine and is metabolized into creatine within the body (Melloni et al. 1979). The increased urinary values are derived from the degradation of creatine into creatinine through the typical biochemical pathways. Only one study investigated the ability of COP to improve muscular performance (Nicaise 1975). Fifty female patients were treated intramuscularly and intravenously with COP and performance tested utilizing a Martin Vigorimeter to measure muscle strength in both hands. The administration of COP resulted in a statistically significant improvement in hand strength.

\section{Creatine-containing nutritional formulations}

Since a number of studies have reported that CM supplementation can increase performance and/or training adaptations, there has been interest in determining whether ingesting creatine with other potentially ergogenic nutrients may affect performance and/or training adaptations to a greater degree. For example, studies have indicated that ingesting creatine with vitamin and mineral-fortified carbohydrate and protein supplements promote greater gains in strength and fat-free mass than carbohydrate or carbohydrate and protein supplements alone (Kreider et al. 1996, 1999; Cribb et al. 2007a; Kreider et al. 1998). Additionally, co-ingesting creatine with different types of protein may have differential effects on gains in fat-free mass and/or training adaptations (Kerksick et al. 2007; Cribb et al. 2007b). Several studies have also indicated that coingesting CM with other potentially ergogenic nutrients such as beta-hydroxy-beta-methylbutyrate (HMB) (Jowko et al. 2001), beta-alanine (Hoffman et al. 2006), phosphates (Eckerson et al. 2005), and alpha-lipoic acid (Burke et al. 2003b) may have some additive effects. While not all studies have reported statistically significant differences, these studies and others support contentions that including $\mathrm{CM}$ in nutritional formulations may promote additive and/ or synergistic effects on training and/or performance.

\section{Regulatory status}

\section{USA}

The legal and regulatory status of creatine forms other than CM in the USA, the largest market worldwide for dietary supplements, is somewhat ambiguous. According to US law, a "dietary supplement" is defined as "... a product (other than tobacco) intended to supplement the diet that bears or contains one or more of the following dietary ingredients: a vitamin; a mineral; an herb or other botanical; an amino acid; a dietary substance for use by man to supplement the diet by increasing the total dietary intake; or a concentrate, metabolite, constituent, extract..." (Federal Food, Drug and Cosmetic Act 1938a). Creatine, an amino acid derivative, would appear to satisfy this requirement. A "new dietary ingredient" (NDI) is defined as "... a dietary ingredient that was not marketed in the United States before October 15, 1994..." The law considers a dietary supplement that contains a new dietary ingredient adulterated, unless the ingredient has been present in the food supply as an article used for food in a form in which the food has not been chemically altered, or there is a history of safe use of the ingredient and that the ingredient is the subject of a 75-day premarket notification to the Food and Drug Administration (FDA) (Federal Food, Drug and Cosmetic Act 1938b). The requirement for the notification to FDA prior to entering the market is to demonstrate to the agency that the ingredient, as intended to be used, is reasonably expected to be safe.

The legal and regulatory status of CM is unequivocal. CM first appeared on the US market in 1993 (EAS 1993) and therefore is not an NDI and instead is considered "Grandfathered" (i.e., a dietary ingredient marketed in the USA prior to 15 October 1994). Furthermore, it satisfies the statutory requirement of having been present in the food supply in a form that has not been chemically altered. Since 1994, many new alternate forms of creatine have entered the US marketplace, and only several of these have been subjected to the requisite 75-day new dietary ingredient notification (NDIN) to FDA. These alternate forms of creatine include, but may not be limited to, CC, CEE, COP, CPY, creatine malate (CML), creatine phosphate $(\mathrm{CP})$, creatine-L-carnitinate (CLC), and tricreatine orotate (TCO). Of these, only CEE, CPY, CLC and TCO have been the subject of an NDI to the FDA, submitted to the agency between 1998 and 2004 (FDA 1995). The FDA has objected to each notification (with the exception of CPY where no decision has yet been posted) citing one or more of the following reasons as the basis for their objection:

1. the form(s) of creatine may not be legal dietary ingredients as defined by the FD\&C Act $\$ 201$ (ff);

2. inadequate information to conclude that the form(s) of creatine is reasonably expected to be safe due to insufficient safety data and/or failure to establish a history of safe use; and/or,

3. inadequate information about the chemical identity of the creatine form(s)

In each of its letters of objection, FDA includes the following text: "Therefore, your product may be adulterated under 21 U.S.C 342(f)(1)(B) as a dietary supplement that contains a new dietary ingredient for which there is inadequate information to provide reasonable assurance that such ingredient does not present a significant or 
unreasonable risk of illness or injury. Introduction of such a product into interstate commerce is prohibited under 21 U.S.C. 331(a) and (v)..."

Due to the nature of the notification process in the USA, a non-response from FDA could, in theory, be considered a "non-objection" from the agency. Thus, the agency's view on the regulatory status of CPY remains unclear. However, with the notification process, FDA maintains the right to object at any time, whether it has previously responded or not. Thus, with the exception of CM and perhaps CPY, other forms of creatine appear to be on the US market without the proper sanction from FDA or without notification to FDA altogether.

\section{Canada}

In Canada, creatine is considered a natural health product (NHP), the regulation of which is administered by the Natural Health Products Directorate (NHPD) of Health Canada (NHPD 2003). The NHP regulation requires that all NHP products be licensed and approved by the NHPD, and each is assigned an eight-digit numerical code. With respect to ingredients, the NHPD has developed a compendium of monographs as a tool to assist with the review of the safety and efficacy of many commonly used NHPs (NHPD 2007). This allows applicants to reference an NHPD monograph in support of their product license application and circumvents the need to evaluate ingredients already known to be safe and efficacious when used under the conditions specified in the NHPD monograph. For creatine, only CM has been approved for use in NHPs and was recently assigned a monograph by the NHPD (NHPD 2008). At present, there are 17 creatine-containing licensed and approved NHPs, all of which contain CM (NHPD 2010).

\section{European Union}

In the EU, creatine is regulated as a food supplement under the Food Supplement Directive (FSD) (EPC 2002) and the directive on substances that may be added for specific nutritional purposes in foods for particular nutritional uses (FPNU) (EPC 2001). In 2004, the European Food Safety Authority (EFSA) issued a positive opinion on CM for FPNU (EFSA 2004). No other opinions have been issued on any other creatine forms, either by EFSA or its predecessor (the Scientific Committee on Food, SCF).

\section{Japan}

In Japan, dietary substances are legally classified as food, food additives, or "non-drug" (food), and are subject to one of two regulations, both enforced by the Ministry of
Health, Labor and Welfare (MHLW). CM is categorized as a "non-drug" (MHLW 2009) and is permitted for use as both a food ingredient and a food additive under the Food Sanitation Law (MHLW 2001), allowing it to be imported, distributed, and produced as food in Japan.

New forms of creatine must be approved by the MHLW before they can be imported, distributed, and produced in Japan, one requirement being that sufficient documentation on the safety and similarity to $\mathrm{CM}$ must be provided. Currently, two new forms of creatine, CC, and CPY have been approved for import to Japan.

\section{South Korea}

In South Korea, the category of dietary supplements was established through legislation in 2004 and is regulated by the Korean Food and Drug Administration (KFDA) (Shimizu 2008). New ingredients must be approved by KFDA and are required to have sufficient toxicological and human clinical trial data supporting the safety and efficacy of the recommended daily dosage. An application for registration of CM was filed with the KFDA in 2005 and was approved for use in dietary supplements in 2008, along with an accompanying health claim (KFDA 2009). At present, no other forms of creatine have been approved for use in South Korea.

\section{Brazil}

In Brazil, nonessential nutrients (such as creatine) are regulated as bioactives or novel food ingredients and must receive approval from the Brazilian National Sanitary Surveillance Agency (or ANVISA) before entering the marketplace (Lajolo and Miyazaki 2007) the approval is based on a comprehensive review of the safety and efficacy of the ingredient and establishes specific requirements for dosage and purity levels, and approved label claims, among other important parameters. ANIVSA recently approved the use of CM in foodstuffs for athletes (reference "Regulations concerning foodstuffs for athletes”. Chapter III, Article 10. The National Health Surveillance Agency Collegiate Board of Directors. 2010). Thus far, Brazil is the only Latin American country to approve the use of creatine and this approval applies specifically to CM.

\section{Analysis}

The legal and regulatory status of CM is unequivocal in the major global markets for dietary or food supplements. The status of other creatine forms present in the marketplace and/or subjected, in the case of the USA, to a pre-market notification is less clear. These alternatives to CM are prevalent in the market, yet do not appear to have met the 
necessary statutory or regulatory requirements in any of the countries examined. In countries where regulatory approval is required prior to use, with the exception of Japan (CC and CPY), none of these forms has achieved approval. However, it is possible that at the time of this review, additional decisions may be pending by regulatory authorities.

In the USA, a key determinant triggering the need for an NDIN to FDA is whether an NDI which has been present in the food supply has been chemically altered (Federal Food, Drug and Cosmetic Act 1938b). Chemical alteration of an ingredient is presumed to alter its biologic behavior and hence a separate safety assessment is required to establish reasonable expectation of safety or that the altered ingredient is comparable to the native ingredient in relevant characteristics. The various forms listed in Table 2 appear to meet the criteria of being chemically altered, as they appear to be distinct chemical entities (via covalent bonding) versus $\mathrm{CM}$, and thus all are subject to the requisite premarket NDIN to FDA. Only four of the eight forms have been subjected to such a notification and all but one (CPY, no decision to date) have been objected to by FDA. In its responses, the agency has indicated that the form of creatine may not even be a legal dietary ingredient and/or notifiers have failed to establish a reasonable expectation of safety and/or provided inadequate information on the chemical identity of the given creatine form.

Explanations as to why these alternate creatine forms are prevalent in the marketplace despite not having met the legal and regulatory requirements in the various markets are likely two-fold. Legal definitions of and regulatory requirements for "dietary supplements" (USA and Korea), "food supplements" (EU), "natural health products" (Canada), and "non-drug food additives" (Japan) are complex, differ between countries/regions, and can be confusing. Lack of awareness and/or understanding of the given country's applicable requirements may be one explanation for the lack of compliance on the part of some marketers. To the extent that the laws and regulations are known and understood, inadequate enforcement by regulators can create an environment where noncompliance is perceived to be without consequences, resulting in the forgoing of required registration or notification requirements. In the USA, the increased prevalence of these alternate forms (CEE in particular) in dietary supplement products, with no enforcement action from FDA, has helped to support this misperception.

The public health implications of having unsanctioned or unapproved forms of creatine on the market remain to be fully realized. While classical animal toxicity data (Mertschenk et al. 2001) and short- and long-term clinical safety studies have been conducted in humans (Kreider et al. 2003a; Schilling et al. 2001; Poortmans and Francaux

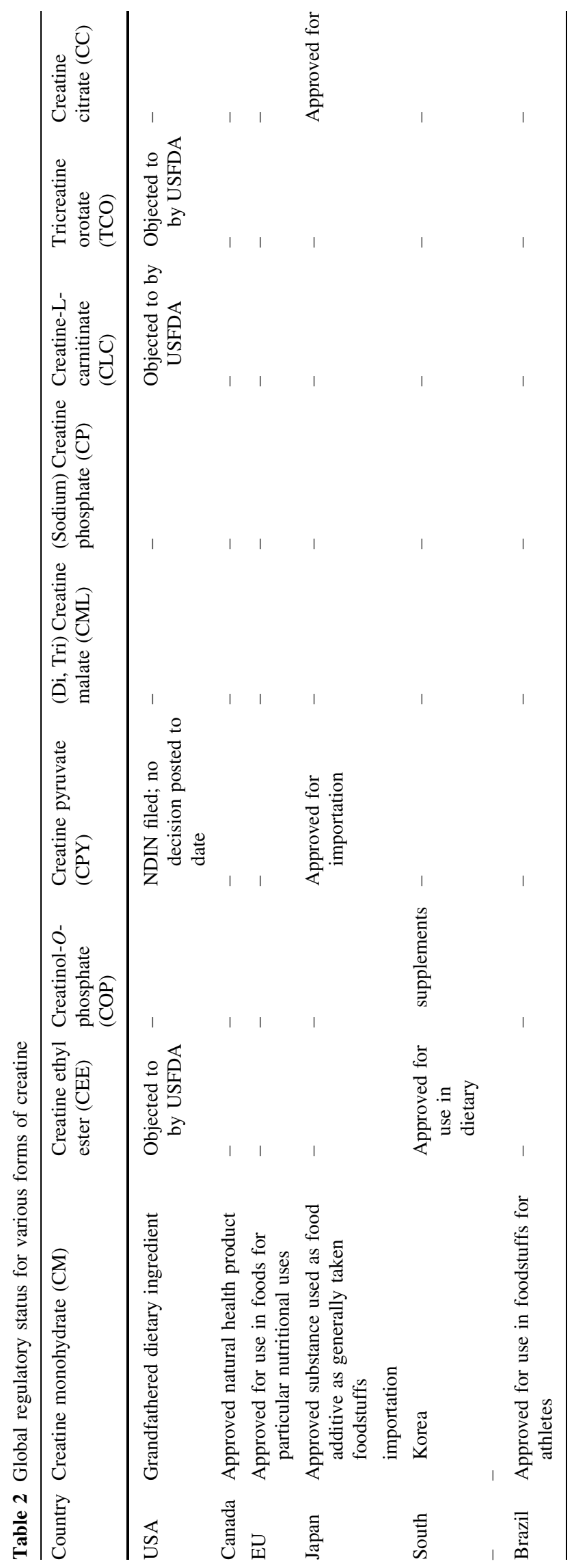


1999; Dalbo et al. 2008), the basic safety data on new forms of creatine is lacking. At present, there do not appear to be any imminent or specific safety concerns associated with any of these alternate forms. However, this must be monitored carefully through post-market surveillance and published case reports. As far as the marketplace is concerned, the presence of these newer and typically more expensive forms of creatine in a multitude of consumer products that are often marketed with misleading and/or unsubstantiated claims of greater bioavailability, efficacy, and safety sets a negative precedent. The reality that companies need not fulfill the necessary registration or notification requirements to satisfy regulatory authorities, but still feel free to market their ingredients/products without penalty establishes an "unlevel" playing field among competitors. This undermines any incentive to invest upfront resources to establish ingredients as safe and efficacious prior to reaching consumers. Inevitably, this will result in unintended and unforeseen consequences, which will serve to erode consumer confidence.

\section{Summary}

Creatine monohydrate supplementation has been consistently reported in the literature to increase muscle phosphagen levels, improve repetitive high-intensity exercise performance, and promote greater training adaptations. Moreover, it has been found to be a stable form of creatine that is not significantly degraded during the digestive process and either taken up by muscle or eliminated in the urine. No medically significant side effects have been reported from CM supplementation despite the widespread worldwide use and the regulatory status of $\mathrm{CM}$ not being well established. Conversely, the efficacy, safety, and regulatory status of most of the newer forms of creatine found in dietary supplements have not been well established. Additionally, there is little to no evidence supporting marketing claims that these newer forms of creatine are more stable, digested faster, and more effective in increasing muscle creatine levels and/or associated with fewer side effects than $\mathrm{CM}$.

Acknowledgments The authors would like to thank all of the research participants and researchers who have contributed to creatine research.

Conflict of interest The authors declare that they have no competing interests. AS is fully employed by a US trade association representing the dietary supplement industry.

Open Access This article is distributed under the terms of the Creative Commons Attribution Noncommercial License which permits any noncommercial use, distribution, and reproduction in any medium, provided the original author(s) and source are credited.

\section{References}

Abraham S, Jiang S (2005) Process for preparing a creatine heterocyclic acid salt and method of use US Patent

Bender A, Samtleben W, Elstner M, Klopstock T (2008) Long-term creatine supplementation is safe in aged patients with Parkinson disease. Nutr Res 28(3):172-178. doi:10.1016/j.nutres.2008.01. 001

Bessman SP, Mohan C (1992) Phosphocreatine, exercise, protein synthesis, and insulin. In: DeDeyn PP, Maresceau B, Statin V, Qureshi IA (eds) Guanidino compounds in biology and medicine. John Libbey and Company, London, pp 181-186

Buford TW, Kreider RB, Stout JR, Greenwood M, Campbell B, Spano M, Ziegenfuss T, Lopez H, Landis J, Antonio J (2007) International Society of Sports Nutrition position stand: creatine supplementation and exercise. J Int Soc Sports Nutr 4:6. doi: 10.1186/1550-2783-4-6

Burke DG, Chilibeck PD, Parise G, Candow DG, Mahoney D, Tarnopolsky M (2003a) Effect of creatine and weight training on muscle creatine and performance in vegetarians. Med Sci Sports Exerc 35(11):1946-1955

Burke DG, Chilibeck PD, Parise G, Tarnopolsky MA, Candow DG (2003b) Effect of alpha-lipoic acid combined with creatine monohydrate on human skeletal muscle creatine and phosphagen concentration. Int J Sport Nutr Exerc Metab 13(3):294-302

Cannon JG, Orencole SF, Fielding RA, Meydani M, Meydani SN, Fiatarone MA, Blumberg JB, Evans WJ (1990) Acute phase response in exercise: interaction of age and vitamin $\mathrm{E}$ on neutrophils and muscle enzyme release. Am J Physiol 259 (6 Pt 2):R1214-R1219

Child R, Tallon MJ (2007) Creatine ethyl ester rapidly degrades to creatinine in stomach acid. Paper presented at the International Society of Sports Nutrition 4th Annual Meeting, Las Vegas, NV, June 12, 2007

Cribb PJ, Hayes A (2006) Effects of supplement timing and resistance exercise on skeletal muscle hypertrophy. Med Sci Sports Exerc 38(11):1918-1925. doi:10.1249/01.mss.0000233790.08788.3e

Cribb PJ, Williams AD, Hayes A (2007a) A creatine-proteincarbohydrate supplement enhances responses to resistance training. Med Sci Sports Exerc 39(11):1960-1968. doi:10.1249/ mss.0b013e31814fb52a

Cribb PJ, Williams AD, Stathis CG, Carey MF, Hayes A (2007b) Effects of whey isolate, creatine, and resistance training on muscle hypertrophy. Med Sci Sports Exerc 39(2):298-307. doi: 10.1249/01.mss.0000247002.32589.ef

Dalbo VJ, Roberts MD, Stout JR, Kerksick CM (2008) Putting to rest the myth of creatine supplementation leading to muscle cramps and dehydration. Br J Sports Med 42(7):567-573. doi:10.1136/ bjsm.2007.042473

Dash AK, Mo Y, Pyne A (2002) Solid-state properties of creatine monohydrate. J Pharm Sci 91(3):708-718. doi:10.1002/jps. 10073

Deldicque L, Decombaz J, Zbinden Foncea H, Vuichoud J, Poortmans JR, Francaux M (2008) Kinetics of creatine ingested as a food ingredient. Eur J Appl Physiol 102(2):133-143. doi:10.1007/ s00421-007-0558-9

EAS (1993) Product Phosphagen ${ }^{\mathrm{TM}}$ marketed by Experimental and Applied Sciences (EAS ${ }^{\mathrm{TM}}$ ). http://www.eas.com

Eckerson JM, Stout JR, Moore GA, Stone NJ, Nishimura K, Tamura $\mathrm{K}$ (2004) Effect of two and five days of creatine loading on anaerobic working capacity in women. J Strength Cond Res 18 (1):168-173

Eckerson JM, Stout JR, Moore GA, Stone NJ, Iwan KA, Gebauer AN, Ginsberg R (2005) Effect of creatine phosphate supplementation on anaerobic working capacity and body weight after two and six 
days of loading in men and women. J Strength Cond Res 19 (4):756-763. doi:10.1519/R-16924.1

Edgar G, Shiver HE (1925) The equilibrium between creatine and creatinine, in aqueous solution: the effect of hydrogen ion. J Am Chem Soc 47:1179-1188

EFSA (2004) Opinion of the scientific panel on food additives, flavourings, processing aids and materials in contact with food: creatine monohydrate for use in foods for particular nutritional uses. EFSA J 36:1-6

EPC (2001) Commission Directive 2001/15/EC of 15 February 2001 on substances that may be added for specific nutritional purposes in foods for particular nutritional uses. http://eur-lex.europa.eu/ LexUriServ/LexUriServ.do?uri=CELEX:32001L0015:en:NOT

EPC (2002) Directive 2002/46/EC of the European Parliament and of the Council of 10 June 2002 on the approximation of the laws of the Member States relating to food supplements. http://eur-lex. europa.eu/LexUriServ/LexUriServ.do?uri=CELEX:32002L0046: EN:NOT

FDA (1995) 75-day premarket notifications for new dietary ingredients. vol Docket number FDA-1995-S-0039-0001. US Food and Drug Administration

Federal Food, Drug and Cosmetic Act (1938a). §201(ff)

Federal Food, Drug and Cosmetic Act (1938b). §413(a)

Ganguly S, Jayappa S, Dash AK (2003) Evaluation of the stability of creatine in solution prepared from effervescent creatine formulations. AAPS PharmSciTech 4 (2):E25. doi:10.1208/pt040225

Gastner T, Krimmer HP, Güthner T, Sturm W (2005) Use of guanidine compounds as physiological strengthening agents in the form of nutritional supplements, animal feed additives, in cosmetics preparations and as plant stimulants. US Patent

Giese MW, Lecher CS (2009a) Non-enzymatic cyclization of creatine ethyl ester to creatinine. Biochem Biophys Res Commun 388 (2):252-255. doi:10.1016/j.bbrc.2009.07.151

Giese MW, Lecher CS (2009b) Qualitative in vitro NMR analysis of creatine ethyl ester pronutrient in human plasma. Int J Sports Med 30(10):766-770. doi:10.1055/s-0029-1231045

Godfraind T, Ghiradi P, Ferrari G, Cassagrande C (1983) Creatinol$O$-Phopshate having therapeutical action. US Patent

Graef JL, Smith AE, Kendall KL, Fukuda DH, Moon JR, Beck TW, Cramer JT, Stout JR (2009) The effects of four weeks of creatine supplementation and high-intensity interval training on cardiorespiratory fitness: a randomized controlled trial. J Int Soc Sports Nutr 6:18. doi:10.1186/1550-2783-6-18

Green AL, Hultman E, Macdonald IA, Sewell DA, Greenhaff PL (1996a) Carbohydrate ingestion augments skeletal muscle creatine accumulation during creatine supplementation in humans. Am J Physiol 271 (5 Pt 1):E821-E826

Green AL, Simpson EJ, Littlewood JJ, Macdonald IA, Greenhaff P (1996b) Carbohydrate ingestion augments creatine retention during creatine feeding in humans. Acta Physiol Scand 158:195-202

Greenhaff P (1997a) Creatine supplementation and implications for exercise performance. In: Jeudendrup A, Brouns M, Brouns F (eds) Advances in training and nutrition for endurance sports. Novartis Nutrition Research Unit, Maasticht

Greenhaff P (1997b) The nutritional biochemistry of creatine. J Nutr Biochem 11:610-618

Greenhaff P, Bodin K, Harris R, Hultman E, Jones DG, McIntyre D, Soderlund K, Turner DL (1993) The influence of oral creatine supplementation on muscle phosphocreatine resynthesis following intense contraction in man. J Physiol 467:75P

Greenwood M, Kreider RB, Rasmussen C, Almada AL, Earnest CP (2001) D-Pinitol augments whole body creatine retention in man. J Exerc Physiol Online 4(4):41-47

Greenwood M, Kreider RB, Earnest C, Rasmussen C, Almada A (2003) Differences in creatine retention among three nutritional formulations of oral creatine supplements. J Exerc Physiol Online 6:37-43

Guglielmi G, Mammarella A (1979) A controlled clinical study of the use of creatinol-O-phosphate in subjects with deficient myocardial circulation. Clin Ter 91(4):355-382

Harris RC, Soderlund K, Hultman E (1992a) Elevation of creatine in resting and exercised muscle of normal subjects by creatine supplementation. Clin Sci (Colch) 83(3):367-374

Harris RC, Soderlund K, Hultman E (1992b) Elevation of creatine in resting and exercised muscle of normal subjects by creatine supplementation. Clin Sci (Lond) 83(3):367-374

Haughland RB, Chang DT (1975) Insulin effects on creatine transport in skeletal muscle. Proc Soc Exp Biol Med 148:1-4

Hoffman J, Ratamess N, Kang J, Mangine G, Faigenbaum A, Stout J (2006) Effect of creatine and beta-alanine supplementation on performance and endocrine responses in strength/power athletes. Int J Sport Nutr Exerc Metab 16(4):430-446

Howard AN, Harris RC (1999) Compositions containing creatine. US Patent

Hultman E, Soderlund K, Timmons JA, Cederblad G, Greenhaff PL (1996) Muscle creatine loading in men. J Appl Physiol 81 (1):232-237

Ivy JL (1998) Effect of pyruvate and dihydroxyacetone on metabolism and aerobic endurance capacity. Med Sci Sports Exerc 30 (6):837-843

Jäger R (2003) The use of creatine monohydrate in sports nutrition, Freising, Germany

Jäger R, Harris RC, Purpura M, Francaux M (2007) Comparison of new forms of creatine in raising plasma creatine levels. J Int Soc Sports Nutr 4:17. doi:10.1186/1550-2783-4-17

Jäger R, Kendrick I, Purpura M, Harris R, Ribnicky D, Pischel I (2008a) The effect of Russian tarragon (Artemisia dracunculus L.) on the plasma creatine concentration with creatine monohydrate administration. J Int Soc Sports Nutr 5(Suppl 1):P4

Jäger R, Metzger J, Lautmann K, Shushakov V, Purpura M, Geiss KR, Maassen N (2008b) The effects of creatine pyruvate and creatine citrate on performance during high intensity exercise. J Int Soc Sports Nutr 5:4. doi:10.1186/1550-2783-5-4

Jowko E, Ostaszewski P, Jank M, Sacharuk J, Zieniewicz A, Wilczak J, Nissen S (2001) Creatine and beta-hydroxy-beta-methylbutyrate (HMB) additively increase lean body mass and muscle strength during a weight-training program. Nutrition 17(78):558-566

Katseres NS, Reading DW, Shayya L, Dicesare JC, Purser GH (2009) Non-enzymatic hydrolysis of creatine ethyl ester. Biochem Biophys Res Commun 386(2):363-367. doi:10.1016/j.bbrc.2009. 06.037

Kerksick CM, Rasmussen C, Lancaster S, Starks M, Smith P, Melton C, Greenwood M, Almada A, Kreider R (2007) Impact of differing protein sources and a creatine containing nutritional formula after 12 weeks of resistance training. Nutrition 23 (9):647-656. doi:10.1016/j.nut.2007.06.015

Kerksick CM, Wilborn CD, Campbell WI, Harvey TM, Marcello BM, Roberts MD, Parker AG, Byars AG, Greenwood LD, Almada AL, Kreider RB, Greenwood M (2009) The effects of creatine monohydrate supplementation with and without D-pinitol on resistance training adaptations. J Strength Cond Res 23(9):26732682. doi:10.1519/JSC.0b013e3181b3e0de

Kessel K, Scherr G, Bogenstätter T, Berndl G, Breitenbach J (2004) Process for producing solid creatine dosage forms and dosage forms obtainable thereby. US Patent

KFDA (2009) Korea Food \& Drug Administration. 기능성 원료 인정 현황. vol 50

Kraemer WJ, Volek JS (1999) Creatine supplementation. Its role in human performance. Clin Sports Med 18 (3):651-666, ix 
Kreider RB (2003) Effects of creatine supplementation on performance and training adaptations. Mol Cell Biochem 244(1-2):8994

Kreider RB, Klesges R, Harmon K, Grindstaff P, Ramsey L, Bullen D, Wood L, Li Y, Almada A (1996) Effects of ingesting supplements designed to promote lean tissue accretion on body composition during resistance training. Int J Sport Nutr 6(3):234-246

Kreider RB, Ferreira M, Wilson M, Grindstaff P, Plisk S, Reinardy J, Cantler E, Almada AL (1998) Effects of creatine supplementation on body composition, strength, and sprint performance. Med Sci Sports Exerc 30(1):73-82

Kreider RB, Klesges RC, Lotz D, Davis M, Cantler E, HarmonClayton K, Dudley R, Grindstaff P, Ramsey L, Bullen D, Wood L, Almada A (1999) Effects of nutritional supplementation during off-season college football training on body composition and strength. J Exerc Physiol online 2(2):24-39

Kreider RB, Melton C, Rasmussen CJ, Greenwood M, Lancaster S, Cantler EC, Milnor P, Almada AL (2003a) Long-term creatine supplementation does not significantly affect clinical markers of health in athletes. Mol Cell Biochem 244(1-2):95-104

Kreider RB, Willoughby DS, Greenwood M, Parise G, Payne E, Tarnopolsky MA (2003b) Effects of serum creatine supplementation on muscle creatine content. J Exerc Physiol online 6 (4):24-33

Kreider RB, Wilborn CD, Taylor L, Campbell B, Almada AL, Collins R, Cooke M, Earnest CP, Greenwood M, Kalman DS, Kerksick CM, Kleiner SM, Leutholtz B, Lopez H, Lowery LM, Mendel R, Smith A, Spano M, Wildman R, Willoughby DS, Ziegenfuss TN, Antonio J (2010) ISSN exercise \& sport nutrition review: research \& recommendations. J Int Soc Sports Nutr 7:7. doi: $10.1186 / 1550-2783-7-7$

Lajolo FM, Miyazaki E (2007) Functional foods legislation in Brazil. In: Losso JN, Shahidi F, Bagchi D (eds) Anti angiogenic functional and medicinal foods. CRC Press, Oakville

Melloni GF, Minoja GM, Lureti GF, Merlo L, Pamparana F, Brusoni B (1979) Acute clinical tolerance of creatinol- $O$-phosphate. Arzneimittelforschung 29(9A):1477-1479

Mertschenk B, Gloxhuber C, Wallimann T (2001) Health assessment of creatine as dietary supplement. Deutsche LebensmittelRundschau 97(7):250-257

MHLW (2001) Director of Standards Division, Dept of Food Safety, Pharmaceutical and Food Safety Bureau. Ministry of Health, Labor and Welfare.「『医薬品的効能効果を標ぼうしない限 り食品と認始れる成分本質(原材料)の取扱い』の改正に ついて」

MHLW (2009) Bureau of Social Welfare and Public Health, Tokyo Metropolitan Government: 「医薬品的効能効果を標ぼうしな い限り医薬品と判断しない成分本質(原材料)リス卜」。 http://www.fukushihoken.metro.tokyo.jp/kenkou/kenko_shokuhin/ken_syoku/kanshi/seibun/index.html

NBJ (2009) Sports nutrition \& weight loss report. Nutrition Business Journal, vol XIV, September edn., Boulder

Negrisoli G, Del Corona L (1997) Hydrosoluble organic salts of creatine. Italy Patent

NHPD (2003) Natural Health Products Directorate (NHPD). http://www.hc-sc.gc.ca/dhp-mps/prodnatur/applications/licenprod/monograph/mono_list-eng.php

NHPD (2007) Natural Health Products Directorate. Compendium of Monographs, vol Version 2.1. Health Canada

NHPD (2008) Natural Health Products Directorate. Creatine Monohydrate. Health Canada

NHPD (2010) Natural Health Products Directorate. Health Canada. http://www.hc-sc.gc.ca/dhp-mps/prodnatur/applications/licenprod/lnhpd-bdpsnh-eng.php
Nicaise J (1975) Creatinol- $O$-phosphate (COP) and muscular performance: a controlled clinical trial. Curr Ther Res Clin Exp 17 (6):531-534

Nuuttilla S (2000) Edustusmelojat testasivat kreatiinipyruvaatin. Suomen urheilulehti 23 (4)

Persky AM, Brazeau GA, Hochhaus G (2003) Pharmacokinetics of the dietary supplement creatine. Clin Pharmacokinet 42(6):557574

Pischel I, Weiss S (1996) New creatine pyruvate derivatives from crystallisation in polar solvents. Germany Patent

Pischel I, Weiss S, Gloxhuber C, Mertschenk B (1999) Creatine ascorbates and a method of producing them. US Patent

Poortmans JR, Francaux M (1999) Long-term oral creatine supplementation does not impair renal function in healthy athletes. Med Sci Sports Exerc 31(8):1108-1110

Purpura M, Pischel I, Jäger R, Ortenburger G (2005) Solid and stable creatine/citric acid composition(s) and compositions of carbohydrate(s) or hydrates thereof, method for the production and use thereof. US Patent

Rooney K, Bryson J, Phuyal J, Denyer G, Caterson I, Thompson C (2002) Creatine supplementation alters insulin secretion and glucose homeostasis in vivo. Metabolism 51(4):518-522

Schilling BK, Stone MH, Utter A, Kearney JT, Johnson M, Coglianese R, Smith L, O'Bryant HS, Fry AC, Starks M, Keith R, Stone ME (2001) Creatine supplementation and health variables: a retrospective study. Med Sci Sports Exerc 33(2):183-188

Shimizu T (2008) Korean latest conditions of health food labeling. Food Style 12(1):54-56

Smith AE, Walter AA, Herda TJ, Ryan ED, Moon JR, Cramer JT, Stout JR (2007) Effects of creatine loading on electromyographic fatigue threshold during cycle ergometry in college-aged women. J Int Soc Sports Nutr 4:20. doi:10.1186/1550-2783-4-20

Spillane M, Schoch R, Cooke M, Harvey T, Greenwood M, Kreider R, Willoughby DS (2009) The effects of creatine ethyl ester supplementation combined with heavy resistance training on body composition, muscle performance, and serum and muscle creatine levels. J Int Soc Sports Nutr 6:6. doi:10.1186/15502783-6-6

Steenge GR, Simpson EJ, Greenhaff PL (2000) Protein- and carbohydrate-induced augmentation of whole body creatine retention in humans. J Appl Physiol 89(3):1165-1171

Ullmann (1995) Environmental Protection and Industrial Safety II. Ullmann's Encyclopedia of Industrial Chemistry, vol B8, 5 edn

Van Schuylenbergh R, Van Leemputte M, Hespel P (2003) Effects of oral creatine-pyruvate supplementation in cycling performance. Int J Sports Med 24(2):144-150. doi:10.1055/s-2003-38400

Volek JS, Kraemer WJ, Bush JA, Boetes M, Incledon T, Clark KL, Lynch JM (1997) Creatine supplementation enhances muscular performance during high-intensity resistance exercise. J Am Diet Assoc 97(7):765-770

Volek JS, Duncan ND, Mazzetti SA, Staron RS, Putukian M, Gomez AL, Pearson DR, Fink WJ, Kraemer WJ (1999) Performance and muscle fiber adaptations to creatine supplementation and heavy resistance training. Med Sci Sports Exerc 31(8):1147-1156

Wang ZQ, Ribnicky D, Zhang XH, Raskin I, Yu Y, Cefalu WT (2008) Bioactives of Artemisia dracunculus L. enhance cellular insulin signaling in primary human skeletal muscle culture. Metabolism 57 (7 Suppl 1):S58-S64. doi:10.1016/j.metabol.2008.04.003

Willoughby DS, Rosene J (2001) Effects of oral creatine and resistance training on myosin heavy chain expression. Med Sci Sports Exerc 33(10):1674-1681

Willoughby DS, Rosene JM (2003) Effects of oral creatine and resistance training on myogenic regulatory factor expression. Med Sci Sports Exerc 35(6):923-929 